\title{
The Hammond Organ
}

\author{
By Sir James Barrett, K.B.E., C.B., C.M.G.
}

A

GENEROUS but anonymous donor has just presented a Hammond organ to the University of Melbourne; and as I am interested in music, especially orchestral music, I am glad to testify to the excellent results obtained from it. The instrument itself is about the size of a small harmonium; it has two manuals and a pedal register, and a foot lever for producing variation in volume. When used fully, the volume of tone is very great, but the musical beauty of the instrument lies even more in the solo stops or arrangements. The clarionet stop produces something superior to any clarionet I have heard, and the volume of tone can be altered at pleasure. The oboe and violin equivalents are very satisfactory.

By combining the various overtones it is obvious that any instrument can be imitated and even improved. The only adverse criticism I have heard is that when the instrument is used fortissimo it is apt to produce a somewhat raucous tone, but that is a matter for the organist to rectify. As the instrument costs about $£ 800$, it seems unlikely that many expensive pipe organs will be built in future; and I have no doubt that the Hammond organ represents the commencement of a new development in music.

The following account of the mechanism was kindly furnished me by the professor of physics in the University of Western Australia, Dr. A. D. Ross :

"A synchronous motor rotates at constant speed a shaft provided with sixty-one iron disks, each fitted with a series of projections like teeth. The speed of rotation and the number of projections is such that for any disk the number of projections passing a given point per second is equal to the frequency of the note represented by the disk. When a key of the keyboard is depressed, a magnet is brought close up to the circumference of the associated disk. The passage of the projections of the iron disk causes periodic fluctuations in the magnetic field of the magnet, and consequent induced current in a coil wound on the pole piece of the magnet. The electro- motive force for this current varies harmonically, so that the current when supplied to a loud speaker gives a sine-wave movement to the speaker diaphragm and therefore a pure tone. (Unfortunately the material of the diaphragm has its own natural harmonics which are introduced to a slight extent into the tone, and this is one of the chief practical defects in the instrument.)

"When the key middle $\mathrm{C}$ of the keyboard is depressed, not only is a magnet brought up to the disk corresponding to frequency 256 , but other magnets to the disks for $512,768,1024$, etc. (the overtones). Each gives alternating electromotive forces with the above-mentioned periodicities, and resultant currents. These currents all pass through separate variable resistances, controlled by the draw-stops (each of which can be moved in or out in eight stages) and so one can utilize the series of electromotive forces corresponding to frequencies 256,768 , etc., in any desired degree of intensity. When the electromotive forces, so adjusted, are applied to a circuit, a current flows with fluctuations corresponding to all the effects superposed. This is amplified and transmitted to the loud speakers, which must produce a sound which has the same fluctuations and is the combination tone with the several harmonics present in the arranged proportions.

"The sounds given out by orchestral instruments have been investigated by recording the air pressure fluctuations in each wave. These waves are then analysed by Fourier analysis, either mathematically or experimentally, and the harmonics present are found and their relative intensities. (The problem is identical with that of tidal analysis.)

"The Hammond organ can undoubtedly produce a wealth of tone shades different from those of any known instruments. I found it most interesting when experimenting with it to alter a tone in a series of steps (each of which was in itself practically imperceptible) from that of a clarinet to that of the flute or oboe."

\section{Industrial Use of Electric Batteries}

$\mathrm{E}^{\mathrm{L}}$ LECTRICAL engineers have recently been considering the relative merits of vehicles driven by electric batteries and of those driven by petrol. Considerable difference of opinion exists on this point, and so the paper by Dr. Strohe, of Cologne, a translation of which appears in World Power of June, is of value as he gives the results of practical tests on the two classes of vehicle.

Dr. Strohe summarizes the relative performances of an electric and a petrol vehicle as follows. Electric vehicles have a life of twenty years and their maintenance costs are five per cent. Petrol vehicles have a life of ten years and their maintenance costs are ten per cent. 'The 'fuel' costs of the latter are about four times greater than that of the former. The capital cost of the large electric vehicle is now lower than that of a petrol vehicle of similar loading capacity, and in addition the oil required is less and the tires last longer. The economic advantages, therefore, are in favour of the electric vehicle. The results show that the daily performance of an electric commercial vehicle after several years' use lies between 18 and 24 miles, and it can double this distance on one battery charge. Electrical vehicles are now available with speeds up to twenty miles per hour; but the radius can be extended by in. creasing the size of the battery. Increasing the size of the batteries is only advantageous when the 
batteries are in full-time use. Otherwise the heavier batteries mean additional non-paying load.

When the huge alternating current network of the Grid supply was completed, many thought that there would be little further use for storage batteries in connexion with lighting supply. Having practically obtained standardization, it is most unlikely that Great Britain will ever drift back into the large variety of voltages and systems of supply which existed before the advent of the Grid. There have been a few breakdowns and blackouts since the early years of its working, but their number is diminishing. In Electrical Industries of May 6, E. C. McKinnon raises the interesting point whether their number is not a secondary consideration to the question of the possibility of their ever occurring at all. The national supply is now so great that to consider emergency duplicates or alternatives for all of it is impracticable, but there are many sections of the community which might be imperilled in the absence of light and power. Statistics show that the list of installations where an alternative supply has been provided so as to be available in the remote possibility of the cutting off of the main supply by storm, riot, enemy's action, etc., is rapidly mounting. Engineers who have been studying the question of emergency plant recognize that there must be no appreciable time lost after a breakdown in putting it into commission.

It has been customary in the past to regard the average working life of a battery of the stationary type to be something over ten years. But this assumes that the battery has been working during this period.
A battery that is only used for standby purposes has a much longer life. It is unlikely that any system of telephone supply would be run solely from the public mains. There is always a storage battery in reserve and so continuity of supply is assured. Proprietors of cinemas are compelled by law to instal a lighting supply secondary to the main supply.

The use of the storage battery as the nucleus for the alternative supply is now firmly established. In several hospitals the storage battery is introduced as a means of assuring constant illumination. The chances of interruption of the public supply are very small, but the outlay required to ensure an unfailing brilliant illumination by a storage battery with automatic control is not a serious item and might possibly save the life of a patient. In stores and public buildings the object of installing automatic emergency lighting devices is to prevent panic amongst those present and the prevention of pilfering should there be a breakdown of the main supply.

In central electric stations and electricity works standby batteries are much used to help carry over the peak loads and so delay the inevitable purchase of more generating plant. A large standby battery in a London supply station was kept fully charged by allowing a 'trickle' of current to flow continuously through it. When recently subjected to the annual examination it was found, for all intents and purposes, to be equal to new after nine years' running.

\section{Turf Nurseries}

$\mathrm{T}$ HE experimental planting work carried out by Sir John Stirling Maxwell at Corrour in Inverness-shire over a long period of years has attained an almost, if not complete, world fame. It was a study of the Belgian system of turf planting which gave Sir John his first successes at Corrour. Since then he has inaugurated what may be considered a sound technique in afforestation work in this type of country.

Sir John has now applied the wide experience gained to the nursery. In the Scottish Forestry Journal, 50, Pt. 1 (Edinburgh, March 1936), he describes his method in an article entitled "Turf Nurseries". It is obvious, says the author, that the method has a restricted application; it can only be practised where peat beds are available. The method was suggested by the ease with which it was found possible to move trees planted on upturned turfs for several years after planting. The method is described as follows by the author:

"An area of peat is selected free from roots and boulders. Nothing is more suitable than the Molinia flats which are found on nearly all Scots moors. Turfs are lifted and turned over in continuous rows, leaving a space between the trenches from which they are taken just wide enough to carry the line of upturned turfs. These nurseries are best prepared in the autumn and planted in the spring, but this is not essential. The plants are inserted in the centre of each turf, a plug being cut out by a circular spade. A dressing of manure mixed with sand or gravel is applied to the roots of each plant. The plug is broken up and used to fill up the hole. Well-grown 2-year seedlings are the best plants for the purpose. As regards species, we have hitherto only used Sitka and Norway spruce and Contorta pine, but Japanese larch, which grows well on certain types of peat, should be equally suitable. As regards the size of nurseries, the ideal arrangement would be to have each nursery just large enough to plant an acre so that no plants would have to be carried more than thirty yards. In practice we have generally found it more convenient to make the nurseries rather larger, since the number of suitable sites is limited. After two years' growth in the nursery the plants are ready to move. They are carried on hand barrows, six or eight turfs to a barrow. Enough plants are left in position to make the nursery part of the wood. For Sitka we leave every fifth plant in every other row. For Norway every fourth plant. The remainder are set out at whatever distance is desired. If the heather is long a space has to be cut or pulled for each turf. Sometimes on very steep slopes it is necessary to make a nick to prevent the turf sliding downhill. The setting out is usually done as soon as the second year's growth is complete. It may be asked why the turfs are not cut where required and placed at once in their permanent positions. The answer is that there is great economy in concentrating all the preparatory work in one spot. Also the turfs are heavy to handle when first cut, whereas after two years' exposure they become much lighter." 